\title{
Poder político fiduciario y soberanía popular. Libertad política, confianza y revolución en la filosofía política de Locke
}

\author{
Fiduciary political power and popular sovereignty. Political \\ freedom, trust and revolution in Locke's political philosophy
}

JORDI MUNDÓ**

\begin{abstract}
Resumen: La teoría republicana moderna de la concepción revolucionaria de la soberanía popular tuvo un eslabón fundamental en la filosofía política de John Locke, quien elaboró un argumento en favor de la libertad natural y de la autonomía de juicio de los individuos, y en contra de la sujeción natural y la alienación de la libertad política. Concibe la autoridad política como un poder político fiduciario instituido para el fin del bien público. Cuando los gobernantes actúan para fines distintos de los encomendados, arbitrariamente o por su interés propio, la confianza se pierde y el ejercicio del poder político regresa a las manos del pueblo libre.

Palabras clave: poder fiduciario, libertad política, derecho natural, confianza, revolución, soberanía popular, Locke
\end{abstract}

\begin{abstract}
Modern republican theory of the revolutionary conception of popular sovereignty had a fundamental link in the political philosophy of John Locke, who elaborated an argument in favour of the natural freedom and autonomy of judgment of individuals, and against the natural subjection and alienation of political freedom. He conceives of political authority as a fiduciary political power instituted for the end of public good. When the trustees act for ends other than those entrusted, arbitrarily or for his own interest, trust is forfeited and the exercise of political power returns to the hands of the free people.

Keywords: fiduciary power, political freedom, natural right, trust, revolution, popular sovereignty, Locke
\end{abstract}

Recibido: 11/06/2020. Aceptado: 17/06/2020. Cómo citar este articulo: Mundó, J. (2020). Poder político fiduciario y soberanía popular. Libertad política, confianza y revolución en la filosofía política de Locke. Daimon. Revista Internacional de Filosofía, (81), 35-50. https://doi.org/10.6018/daimon.432081

* Este trabajo se ha desarrollado en el marco del proyecto de investigación PGC2018-094324-B-I00 (MCIU/AEI/ FEDER, UE), sobre "Libertad política, derechos de propiedad, bienes comunes y política pública entendidos como relaciones fiduciarias".

** Profesor Titular de Universidad del Departamento de Sociología, área de Filosofía Moral, de la Universitat de Barcelona. Correo electrónico: jordimundo@ub.edu. Líneas de investigación: relaciones fiduciarias, propiedad, libertad política, republicanismo, Locke, derecho natural, integración causal en las ciencias sociales y envejecimiento y epidemiología social. Trabajos recientes: Mundó, J. (2017), «La constitución fiduciaria de la libertad política. (Por qué son importantes las coyunturas interpretativas en filosofía política)», Isegoría. Revista de Filosofía Moral y Política, 57, Julio-Diciembre, pp. 433-454; Mundó, J. (2017), «Locke's property in historical perspective: natural law and the shaping of modern political common sense», Analele Universitatii din Craiova-Seria Filosofie, 40(2), pp. 19-40. 


\section{Introducción}

El nacimiento del mundo moderno se caracterizó por sociedades políticas en las que proliferaron formas de autoridad política (monarquías absolutas y cuerpos representativos) despóticas o corruptas, así como por los intentos por controlar, limitar y combatir esos poderes arbitrarios. Sobre la base de viejas formas constitucionales heredadas y de nuevas teorizaciones y prácticas políticas anti-absolutistas, tomó fuerza una triple premisa acerca del poder político: su fundamentación iusnaturalista, su sujeción al imperio de la ley y su dependencia constitutiva del consentimiento de los ciudadanos. Sin embargo, en la filosofía política moderna, soberanía y libertad política eran términos que se presentaban en tensión permanente, a menudo concebidos como mutuamente excluyentes. Los monarcas absolutos encarnaron la moderna soberanía como resultado de un doble proceso secular iniciado en los siglos XV y XVI. Por arriba, habían conseguido sacarse de encima el poder imperial decadente del Sacro Imperio Romano Germánico y el poder imperial político-espiritual del Papa de Roma. Por abajo, habían logrado someter con éxito a distintos poderes feudales, reafirmando su monopolio de la fuerza sobre un territorio dado. ${ }^{1}$ En ese contexto, para el absolutismo el ejercicio popular de la libertad política era concebido, bien como imposible -por quienes abogaban, como Filmer, por la sujeción natural al monarca-, bien como indeseable -por quienes defendían, como Hobbes, que la libertad debía ser alienada en favor del soberano absoluto (Tierney, 1997, 2014; Tuck, 1979).

La teoría política de Locke significó una aportación singular que sigue llamando vivamente la atención de la filosofía política contemporánea, pues permitió cohonestar soberanía y libertad política mediante un razonamiento fiduciario que conduce a una concepción revolucionaria de la soberanía popular. En lo que sigue, mostraremos que Locke sostiene (1) que los individuos son naturalmente libres; (2) que la libertad es inalienable, y (3) que, para consumar el derecho natural a la preservación individual y de la humanidad toda, los individuos consienten en formar una sociedad política, (4) para lo cual confían el ejercicio de su libertad a un poder político constituido únicamente para el fin del bien público. (5) Esta concepción fiduciaria del poder político implica que, cuando los gobernantes violan esta confianza actuando para fines distintos al encomendado, ejerciendo el poder despótica o arbitrariamente, mediante abuso o corrupción, entonces la confianza queda revocada y el ejercicio pleno de la libertad política regresa a las manos del pueblo libre. (6) Cuando los gobernantes despojados de la confianza otorgada persisten en su arbitrariedad, el pueblo tiene el derecho de resistencia e, incluso, de revolución. Así, es el pueblo el que en última instancia puede resolver las controversias entre los poderes constituidos, o entre los ciudadanos y estos poderes, y puede legítimamente volver a confiar el ejercicio de la libertad política en otros gobernantes o instaurar un sistema político enteramente nuevo.

1 En ese proceso, los monarcas rivalizaron con cuatro grupos de autoridades: la principal era la Iglesia, que incluía al Papa pero también a la curia romana y a los representantes de Roma en sus territorios, algunos de los cuales desempeñando un rol destacado como funcionarios reales en cada reino; el segundo poder con el que competían era la nobleza feudal, que gobernaba los feudos locales y que en conjunto conformaba la clase dirigente, a menudo con capacidad para cuestionar y resistir la autoridad real; el tercer rival (en ocasiones, también aliado) eran las autoridades locales (communitates), que podían tener poder autónomo; y, finalmente, a menudo los monarcas competían con el poder de otras monarquías. 


\section{Libertad natural}

La idea de que existe un hiato entre las sociedades modernas y las premodernas tiene una tradición bien arraigada. Cuando Ferguson (1767), Maine (1861) o Tönnies (1880) desarrollan esa distinción, no hacen sino recurrir a un tipo de argumentación ya utilizada por autores tardomedievales y de la modernidad temprana sobre el parecido y la complementariedad entre derecho natural y constitución antigua (Kuttner, 1982; Ashcraft, 1986; Pocock, 1987; Phillipson y Skinner, 1993). En la Inglaterra del siglo XVII, abundan los escritores que consideran que un sistema de gobierno natural (o ad hoc) es similar al de las libertades pre-normandas y sajonas, y al reconocimiento de derechos de nacimiento ingleses presente en escritos constitucionales y republicanos antiguos, como reflejarían el Mirrour of Justices de Horne (1646) -escrito en el siglo XIV-, la historia de las libertades sajonas de Nathaniel Bacon (1647), los propietarios armados de Harrington y el соттиnitas militum de Henry Neville, muchas de las cuales están presentes en las genealogías que describen James Tyrrell, Algernon Sydney, William Temple, William Atwood, John Wildman y William Petyt. Por eso, entre los autores que participaron en el debate del contexto histórico inglés de la Crisis de la exclusión (1679-1681), fue común asociar derecho natural a constitución antigua.

De modo que los viejos republicanos constitucionales y los no tan viejos whigs y radicales iusnaturalistas convergieron tanto en la común consideración de que los cambios sociales y económicos ocurridos debían tener su traducción en las formas de gobierno, como en el juicio favorable a que los gobernados jugaran un rol central -aunque mediado- en la gobernación, como en las teorías de Milton (1991 [1649]), Harrington (1656) Locke (1988 [1681-1689]) y Sydney (1698). Locke escribe los Two Treatises durante la gestación de la insurrección de 1681-1683 como una solución consistente en la reapropiación popular del poder político mediante una revolución, sobre la base de que "the people have a right to act as supreme, and continue the legislative in themselves, or erect a new form, or under the old form place it in new hands, as they think good" (II.243). ${ }^{2}$

Esta solución fiduciaria anti-absolutista está fundada en cuatro cláusulas mutuamente necesarias de la libertad natural:

(1) Autogobierno: el poder político es una propiedad natural de los individuos, por el cual los individuos tienen la capacitad natural de autogobernarse. Esta cláusula, a menudo definida como de "autopropiedad" ("every man has a property in his own person", II.27), reconoce la potestad de cada persona sobre sí misma por derecho propio (sui iuris), algo muy distinto a tener una propiedad absoluta de sí misma (sui dominus). Para Locke, no sólo

2 Para Locke, se trata de un diseño institucional que, por un lado, articula políticamente el hecho de que la libertad, el poder político y la propiedad derivan del pueblo, no del rey, y que, por otro, permite embridar el ejercicio de ese poder en la sociedad política mediante algún tipo de consentimiento fiduciario. Así, en el contexto de la Guerra de los Nueve Años, Locke publica en 1689 una versión ampliada de los Two Treatises en la que aconseja al rey William que el modo de legitimar su poder debía fundarse en "the consent of people, which being the only one of all lawful governements", reconociendo así la soberanía popular (Locke, 1988, Prefacio). (En lo que sigue, para las citas de los Two Treatises se obviará el nombre del autor y únicamente se distinguirá el primer y segundo tratados con números romanos, seguido del número de párrafo; además, dado el preciso significado que tienen los términos fiduciarios lockeanos, se ha optado por mantener las citas en el idioma original). 
las personas no pueden disponer ilimitadamente de sí mismas por ser criaturas de dios ("yet he has no liberty to destroy himself", II.6), sino que además esto es indeseable por cuanto legitimaría la alienación de la libertad política (Mundó, 2005, 2017a, 2017b, 2018).

(2) Ausencia de dominación: los individuos son naturalmente libres en el sentido de no estar naturalmente sujetos a la voluntad arbitraria de otro.

"To understand political power right, and derive it from its original, we must consider what state all men are naturally in, and that is, a state of perfect freedom to order their actions, and dispose of their possessions, and persons as they think fit, within the bounds of the law of nature, without asking leave, or depending upon the will of any other man" (II.4; cf. II.27).

De aquí que al ingresar en la sociedad política, la libertad consista en someterse recíprocamente al poder político instituido por consentimiento fiduciario:

"The liberty of man, in society, is to be under no other legislative power, but that established, by consent, in the commonwealth, nor under the dominion of any will, or restraint of any law, but what the legislative shall enact, according to the trust put in it" (II.22).

(3) Ley entendida como constitutiva de la libertad: la ley civil no está para restringir los deseos naturalmente egoístas de los humanos, sino para promover el deseo humano, naturalmente encauzado por la razón, de una buena vida:

"For law, in its true notion, is not so much the limitation as the direction of a free and intelligent agent to his proper interest, and prescribes no farther than is for the general good of those under that law" (II.57).

Entonces, concebir la conducta dentro de la ley en una sociedad política racionalmente ordenada no implica la disminución de la libertad, sino crear las condiciones de realización de la misma: "the end of the law is not to abolish or restrain, but to preserve and enlarge freedom" (II.57). Así entendido, los ciudadanos no se someten pasivamente a sus gobernantes, sino que estos actúan "by the will of the society, declared in its laws" (II.151).

(4) Reciprocidad en la libertad política: los individuos son naturalmente iguales, por lo que tienen igual derecho y obligación de ejercer el poder político.

"A state also of equality, wherein all the power and jurisdiction is reciprocal, no one having more than another (...). For in that state of perfect equality, where naturally there is no superiority or jurisdiction of one, over another, what any may do in prosecution of that law, everyone must needs have a right to do" (II.4, II.7).

Por eso, "being all equal and independent, no one ought to harm another in his life, health, liberty, or possessions" (II.6). Pero, puesto que esta libertad en el estado de naturaleza es vulnerable a interferencias arbitrarias de otros y está demasiado supeditada a la incerti- 
dumbre, los individuos se unen mediante una sociedad política "for the mutual preservation of their lives, liberties and estates, which I call by the general name, property" (II.123). ${ }^{3}$

\section{Inalienabilidad}

Sin embargo, hay un argumento "moderno" en contra de que las personas afirmen políticamente su libertad natural: se trata de la tesis absolutista partidaria de que los individuos alienen completamente el poder político en favor del monarca, renunciando así al derecho de legítima defensa. Locke conoce bien este razonamiento, pues lo había utilizado en sus Two Tracts (1660). Desde posiciones distintas, Filmer (1991 [1648]) y Pufendorf (1729) abundan en la tesis de que si la monarquía y el parlamento comparten la soberanía, o si las personas evitan renunciar a su derecho natural a juzgar y a ejecutar por sí mismas, entonces, dada la parcialidad humana, esto conducirá a desacuerdos, tumultos y a la guerra civil. Implicará, sostienen, nada menos que regresar a un pasado feudal plagado de conflictos, además de constituir un grave impedimento para la centralización y modernización que distingue a la monarquía absoluta. ${ }^{4}$ Bien es cierto que muchos absolutistas mitigan esta doctrina con excepciones bien conocidas: Grocio (1625) y Pufendorf reconocen que un individuo puede defenderse del ataque de un tirano asesino, y William Barclay (1600) sostiene que el pueblo puede defenderse, generalmente a través de su cuerpo representativo y sin causar daño al rey. Ahora bien, las distintas formas de teorizar política e iusfilosóficamente las realidades históricas modernas que conocemos como monarquías absolutas fueron menos "modernas" de lo que a menudo se supone. Incluso un defensor tan recalcitrante de la soberanía monárquica como Hobbes (2012 [1651]), recurrió, para hacerlo, a vetustas ideas antirrepublicanas del Mediterráneo antiguo: su auctoritas non veritas facit legem revive el ideal imperial romano de la lex animata (y, antes, el ideal helénico postalejandrino de los nomoi empsychoi, los autócratas que encarnan a la ley y están, por eso mismo, por encima de ella), por no hablar del princeps legibus solutus de los teóricos al servicio de los principados absolutistas renacentistas italianos.

Locke presenta varias objeciones al iusnaturalismo alienista, entre las que queremos destacar cinco. La primera sostiene que, puesto que el soberano está por encima de la ley, esto equivale a estar fuera de la ley, con lo que el absolutismo no puede constituir una forma de gobierno de la sociedad política:

"Absolute monarchy, which by some men is counted the only government in the world, is indeed inconsistent with civil society, and so can be no form of civil government at all. For the end of civil society, being to avoid, and remedy those inconveniencies of the state of nature, which necessarily follow from every man's being judge in his own case, by setting up known authority, to which every one of

3 Esta noción de propiedad ha sido interpretada por una parte de la filosofía política contemporánea como mera posesión absoluta, exclusiva y excluyente, hurtándole el significado complejo que deliberadamente le otorgaba Locke (Mundó, 2017a; 2017b; 2018; cf. II.173).

4 Rousseau (1762, I.6), contra la tesis de los Two Treatises de Locke, aduce que si la alienación de la libertad natural no es completa, entonces no existe soberano alguno y el pueblo queda varado en un estado de cuasi naturaleza. 
that society may appeal upon any injury received, or controversy that may arise, and which everyone in society might to obey; wherever any persons are, who have not such an authority to appeal to, for the decision of any difference between them, there those persons are still in the state of nature" (II.90).

En segundo lugar, en términos consecuencialistas, Locke aduce que sería irracional que los individuos enajenaran su libertad, pues les colocaría en una situación de indefensión en la sociedad política (con la imposibilidad de zafarse de los abusos del metafórico león monárquico), que sería manifiestamente peor que la del estado de naturaleza (en el que a lo sumo había que pelearse con mofetas y zorros) (II.93).

En tercer lugar, deontológicamente, como va dicho, para Locke la libertad de los individuos no equivale a una propiedad absoluta sobre sí mismos; pero, además, tampoco implica que sea aceptable una propiedad absoluta sobre otro (II.23). Ambas habilitan la esclavitud, tanto si es voluntaria como si es forzada (Mundó, 2005). En una crítica devastadora, Locke sostiene que, por mucho que el absolutismo haya devenido universal, no deja de ser un poder "despótico", políticamente coextensivo de la "esclavitud", capaz de ejercer un poder ilimitado sobre cualquier ser humano, constituyendo una violación del derecho natural (II.172). Puesto que la libertad natural es constitutiva, no cabe la sujeción ni la alienación absolutas. El ejercicio del poder absoluto del monarca sobre los gobernados, concluye Locke, equivale a una declaración de estado de guerra (II.17).

Una cuarta razón esgrimida por Locke tiene que ver con la escasa verosimilitud histórica de la teoría de la alienación. ¿Es posible que, tras la Reforma y la guerra civil posterior, los individuos consintieran en alienar su libertad? Locke no lo cree así. Precisamente, acaso una de las reflexiones filosóficas de fondo más relevantes de su Essay concerning toleration (Locke, 2006 [1667]) sea la que afirma que los individuos no deben enajenar su derecho a juzgar y desobedecer las leyes que consideran injustas. En los Two Treatises va más lejos aún en su elaboración teórica, sosteniendo que los individuos nunca enajenan su derecho a exigir que la autoridad política cumpla la ley -esto es, que no esté por encima de ella- y actúe de acuerdo con el fin para el que fue instituida. El rechazo de Locke a la concepción absolutista de individuos impolíticos no es una mera cuestión de principio, sino que se apoya también en la experiencia histórica de las guerras de religión y de las políticas de exclusión y persecución de las minorías que no aceptaban la conformidad religiosa (Ashcraft, 1986). Locke incluso bosqueja una sociología moral de la dominación y la resistencia:

"For when the people are made miserable, and find themselves exposed to the ill usage of arbitrary power, cry up their governors, as much as you will for sons of Jupiter, let them be sacred and divine, descended or authorized from heaven, give them out for whom or what you please, the same will happen. The people generally ill treated, and contrary to right, will be ready upon any occasion to ease themselves of a burden that sits heavy upon them. They will wish and seek for the opportunity, which, in the change, weakness, and accidents of humane affairs, seldom delays long to offer itself. He has must have lived but a little while in the world, who has not seen examples of this in his time" (II.224). 
El quinto argumento de rechazo de la alienación también tiene una dimensión históricoempírica: a medida que los gobiernos de la sociedad política se asientan y los aparatos estatales de las monarquías absolutas logran un control político, administrativo y territorial más estable, tienden a acrecentar sus atribuciones y a caer en la arbitrariedad y la tiranía. Además, para desmontar las bondades prácticas de la monarquía absoluta, Locke recurre al argumento ilustrado de la manipulación ideológica del poder político por parte de las élites religiosas (II.94, II.106-112, II.208-10).

En suma, el gobierno absolutista basado en la alienación de la libertad es indeseable, pues se fundaría, en el mejor de los casos, en una confianza hipotética (la de gobernar según el interés del pueblo); pero, cuando esta confianza se quiebra, al haber renunciado al derecho de autodefensa, el pueblo no puede ejercer su autogobierno para combatir eficazmente los abusos de la autoridad política.

\section{Bien público}

Para Locke, el derecho natural constituye la gramática con la que deben articularse los derechos y deberes a la preservación, entendidos estos como fines del poder político instituido: "Political power then I take to be a right of making laws (...) and all this only for the public good" (II.3). El bien público es concebido como la preservación de la humanidad toda (II.135), que se concreta en el doble deber de protección de la sociedad y de cada individuo: "Itself is the preservation of the society and (as far as will consist with the public good) of every person in it" (II.134; cf. I.92; Mundó, 2015, 2017a). ${ }^{5}$ En este sentido, la aplicación del derecho natural para el fin del bien público cumple tres propósitos: constituye el criterio mediante el cual se resuelven las controversias en el estado de naturaleza (II.4, II.7), establece las pautas para la aprobación de leyes y para la actividad política ejecutiva en la sociedad política ("their powers are limited to the public good of the society", II.135; cf. II.143, II.147, II.159) y fija los criterios mediante los que el pueblo juzga a los poderes públicos (II.149, II. 156, II. 165).

En el proceso de ingreso en la sociedad política, cada uno de los individuos -guiado por la razón y el derecho natural- confía su poder político a una autoridad política instituida precisamente para el fin del bien público (la preservación de la sociedad y de los individuos). De este modo, el bien público constituye la limitación inherente del poder político fiduciario (II.171). ${ }^{6} \mathrm{Y}$ es precisamente este criterio el que permite decidir cómo y por qué se ejerce,

5 Esta interpretación de la teoría política de Locke ha sido preterida por una parte de la filosofía política contemporánea, contribuyendo a proyectar un sesgo muy estable sobre su propuesta normativa, reduciéndola a un mero individualismo posesivo (Mundó, 2017a, 2017b, 2018).

6 Locke reproduce aquí una noción que, salvando diferencias substanciales de contexto e intencionalidad normativa, retrotrae a la estructura fiduciaria de la tutela ciceroniana. En De Officiis, Cicerón concibe la administración de la cosa pública como una custodia o tutela encargada de velar por el bienestar de aquellos para los que el poder fiduciario fue instituido: "La administración del gobierno, así como ocurre con la administración de la tutela, debe conducirse para el bien de los tutelados, no para el de aquellos en los que se ha confiado el ejercicio de la misma" (Cicerón, 1928, I.85, traducción mía). Como señala Barker (1934), cuando se trata de la estructura iuspública del poder fiduciario, el principal y el beneficiario son el mismo (el pueblo); en cambio, en muchas relaciones fiduciarias iusprivadas existen tres partes diferenciadas: principal, agente y beneficiario (cf. Johnston, 1998). Para abundar en el carácter fiduciario en la tradición republicana clásica, cf. Domènech (2009). 
justifica, limita y resiste la autoridad política instituida. Además, tal criterio de otorgamiento de confianza constitutivo del gobierno conlleva la necesaria regulación de los medios de preservación (II.50, II.120, II.138; cf. Wood, 1983, 38-39).?

\section{Poder político fiduciario}

Locke, en su propósito de ofrecer una alternativa política al auge del absolutismo, teoriza el paso del estado de naturaleza a la sociedad política como una solución fiduciaria: ${ }^{8}$ por mor del bien público, las personas renuncian a ejercer por sí mismas el poder político de autogobierno que por naturaleza detentan y, a cambio, confían su ejercicio a poderes políticos instituidos para tal fin (II.130). Entonces, los gobernantes deben ejercer el poder político ateniéndose a la confianza otorgada, lo cual comprende: que las leyes deban promulgarse y aplicarse conforme al bien público (II.171), que los propios gobernantes estén sujetos a las leyes que aprueban (II.94) y que estas no puedan modificarse sin el consentimiento de la mayoría a través de sus representantes (II.135, II.140). La condición de miembro de la sociedad política vincula a cada uno a lo que determine la mayoría, hasta que eventualmente se revoque su ciudadanía o se disuelva la sociedad (II.95-9, II.120-2).

Para Locke, republicanamente, el poder legislativo es el "poder supremo" en cualquier sociedad políticamente constituida, puesto que es el poder de hacer leyes y, como va dicho, éste tiene su origen en el poder político natural de cada uno de los miembros para juzgar por sí mismos (I.89, II.212; cf. Mundó, 2015). Aunque lleve el calificativo de "supremo" (en el sentido de ser independiente del poder ejecutivo del monarca y de tener en exclusiva la prerrogativa de aprobar leyes; cf. Gough, 1950, y Phillipson y Skinner, 1993), para Locke en realidad se trata de un poder fiduciario que no puede actuar arbitrariamente:

"The constitution of the legislative is the first and fundamental act of society, whereby provision is made for the continuation of their union, under the direction of persons, and bonds of laws made by persons authorized thereunto, by the consent and appointment of the people" (II.212).

Además, en una relación fiduciaria de segundo orden, es el legislativo el que confía los poderes políticos naturales de la comunidad al ejecutivo para hacer cumplir las leyes y someter su conducta al fin del bien público (II.144-8; cf. Gough, 1950).

7 Para un desarrollo de esta importante dimensión fiduciaria - de la que no podemos ocuparnos aquí por razones de espacio-, véanse Mundó (2017a, 2017b, 2018).

8 Locke había utilizado el razonamiento fiduciario, con un contenido muy distinto, en los Two Tracts (1660; cf. Mundó, 2017a), como lo habían utilizado antecesores próximos como Grocio, Vattel u Overton (Criddle, 2014). Como mostró con agudeza Maitland (1913 [1900], 36) en su introducción a la traducción de la obra de Otto Gierke Political Theories in the Middle Age, en el contexto inglés el concepto de "trust" del derecho privado acabo siendo aplicado al contexto político. Sostiene, por ejemplo, que en el siglo XVIII la expresión "all political power is a trust" ya era un lugar común en el ámbito parlamentario. De modo que, en última instancia, la pertinencia iuspública de la estructura relacional fiduciaria no tiene tanto que ver con esa estructura en sí misma, sino con los fines por lo que se instituye, quién tiene la soberanía y quién el poder delegado, y qué mecanismos se articulan para el control efectivo del poder fiduciario. 
En buena medida, Locke elabora su argumento fiduciario como una desautorización de las tesis de la sujeción natural de Filmer (1991), el cual se pregunta -pertinentemente- por qué los humanos naturalmente libres deberían tener interés en renunciar al ejercicio de su autogobierno en favor de un poder constituido que lo hiciera en su nombre y que gobernara sobre ellos. Locke reformula la pregunta filmeriana del siguiente modo:

"If man in the state of nature be so free, as has been said; if he be absolute lord of his own person and possessions, equal to the greatest, and subject to nobody, why will he part with his freedom? Why will he give up this empire, and subject himself to the dominion and control of any other power?" (II.123).

Interesantemente, Locke ofrece dos argumentos para refutar la acusación de Filmer acerca de la supuesta incongruencia de la delegación de la libertad. El primero ataca la principal premisa filmeriana, pues para Locke es falso que los individuos renuncien completamente a su libertad, por cuanto ningún individuo es señor absoluto ("absolute lord") de sí mismo; renunciar, delegándolo, al ejercicio del poder político natural propio en modo alguno equivale a renunciar a la libertad natural misma. El segundo se refiere a las ventajas comparativas en punto a la seguridad jurídica que tiene la delegación en la sociedad política respecto al autogobierno en el estado de naturaleza: en el estado de naturaleza no rigen leyes bien establecidas, que obliguen a todos por igual y sean de conocimiento público; ni hay jueces imparciales preestablecidos, por lo que los juicios pueden estar guiados por el interés propio y la parcialidad (II.13); y, además, existen obstáculos de toda índole para garantizar que las sentencias se cumplan (II.136). Entonces, la solución fiduciaria coadyuvaría a evitar estos males:

"To avoid these inconveniencies which disorder men's properties in the state of nature, men unite into societies that they may have the united strength of the whole society to secure and defend their properties, and may have standing rules to bound it by which every one may know what is his. To this end it is that men give up all their natural power to the society they enter into, and the community put the legislative power into such hands as they think fit, with this trust, that they shall be governed by declared laws, or else their peace, quiet, and property will still be at the same uncertainty as it was in the state of nature" (II.136).

Locke se muestra particularmente interesado en apoyar sus razonamientos iusnaturalistas fiduciarios en experiencias históricas que refuercen su plausibilidad. Sostiene que en el estado de naturaleza ya era común confiar en una sola persona para que guiara a los demás en tiempos de guerras exteriores. Más adelante, afirma, recurrieron a esta solución para resolver conflictos internos (II.108, II.110, II.112). ${ }^{9}$ Sin embargo, estas prácticas antiguas

9 Este argumento no hace sino corroborar la evidencia de que la solución fiduciaria está bien arraigada en tradiciones muy distintas, pues en realidad se basa en el supuesto de que el soberano (en este caso, el pueblo) no tiene la capacidad, la pericia o el tiempo necesarios para lograr un fin. Para ello, elige -o instituye- a un agente, al que confía el ejercicio de parte de sus poderes para que logre ese fin en su nombre. Por eso, encontramos antecedentes valiosos de relaciones fiduciarias en el derecho romano, pero también en codificaciones hammurábicas, judías e islámicas, por citar sólo algunas (Frankel, 2011; Criddle, Miller y Sitkoff, 2019). 
se basaban en una confianza ingenua, lo que propició que los gobernantes abusaran de la misma, ampliando sus prerrogativas hasta oprimir al pueblo, pues tenían "distinct and separate interests from their people" (II.111).

Aunque en las sociedades políticas esta confianza se haya reforzado mediante mecanismos de control fiduciario más solventes, Locke recela de que pueda fiarse la limitación del poder político delegado al mero derecho a apelar contra las decisiones injustas de los poderes públicos únicamente mediante los cauces legales establecidos. De las luchas de los dissenters de las décadas de 1660 y 1670, aprendió que las reivindicaciones formales por las libertades religiosas eran sistemáticamente bloqueadas, que el poder político era capaz de estigmatizar a grupos minoritarios, acusándoles de "sediciosos" (II.218), y que podía aprobarse una legislación represiva que atara de pies y manos cualquier tipo de disidencia política. ${ }^{10}$ Locke sostiene que la historia de las sociedades políticas ilustra suficientemente que los parlamentos son corruptibles (II.201, II.221-3, II.138, II.149). Y afirma que, a menudo, el poder ejecutivo de los monarcas, incluso en sistemas de monarquía mixta, se ha utilizado de forma abusiva, en ocasiones anulando incluso las limitaciones que formalmente les imponían los parlamentos (II.107, II.111-12, II.163), invalidando de facto el poder fiduciario de estos (II.151-167).

En conclusión, Locke es históricamente consciente de que la asimetría en la relación fiduciaria entre gobernados y gobernantes permite que estos tengan un tipo de discrecionalidad -inherente a todo poder fiduciario- que abre una ventana de oportunidad (y a menudo constituye un incentivo) para interferir arbitrariamente en las acciones y decisiones de los gobernados y perseguir sus propios fines, no los del bien público. De aquí que Locke considere que los derechos de resistencia, rebelión y revolución constituyen una herramienta política fundamental para el control y limitación efectivos del poder político fiduciario.

\section{Resistencia, revolución y soberanía popular}

Entonces, para Locke el problema de fondo se resume en cómo se puede controlar y limitar esos poderes delegados en manos del legislativo y el ejecutivo (y, en cierto sentido, del poder judicial). Atendiendo a la condicionalidad de la delegación del poder político en manos de los gobernantes al cumplimiento del bien público, Locke recalca que es el pueblo libre el que tiene la última palabra, pues en modo alguno ha renunciado a su libertad, y cada uno de sus miembros sigue siendo capaz de juzgar por sí mismo:

"The legislative being only a fiduciary power to act for certain ends, there remains still in the people a supreme power to remove or alter the legislative, when they find the legislative act contrary to the trust reposed in them. For all power given with trust for the attaining an end being limited by that end, whenever that end is manifestly neglected or opposed, the trust must necessarily be forfeited, and the power devolve into the hands of those that gave it, who may place it anew where they shall think best

10 En su ensayo sobre la tolerancia, Locke (1963 [1689]) argumenta que en la separación entre Iglesia y Estado, las instituciones representativas y la Carta de Derechos habían demostrado ser herramientas necesarias pero insuficientes para confrontar la opresión y promover una sociedad libre. 
for their safety and security. And thus the community perpetually retains a supreme power of saving themselves from the attempts and designs of anybody (...)" (II.149).

Y reproduce la misma lógica en lo que atañe al ejecutivo:

"[I]f a controversy arise betwixt a prince and some of the people in a matter where the law is silent or doubtful, and the thing be of great consequence, I should think the proper umpire in such a case should be the body of the people" (II.242).

El punto de apoyo de la palanca de la teoría revolucionaria de la soberanía popular de Locke es que toda persona tiene un derecho político inalienable a alzarse contra los gobernantes que hayan violado la confianza que les fue otorgada para el fin del bien público (II.222, II.224, II.228, II.231, II.232, II.235, II.239, II.242). Por eso, una mayoría del pueblo tiene plena autoridad constituyente para deponer los cargos públicos, reinstaurar una forma de gobierno o establecer una nueva. Lo cual, precisa Locke, no significa un regreso al estado de naturaleza:

"The power that every individual gave the society, when he entered into it, can never revert to the individuals again, as long the society lasts, but will always remain in the community; because without this, there can be no community, no commonwealth" (II.243; cf. Purdy, 2007, 175-180).

Sin embargo, esta teorización fiduciaria del poder político fue recibida con una abierta hostilidad por los monárquicos absolutistas y con evidente animadversión por parte de los whigs moderados. Unos y otros coinciden en la acusación contra Locke de que un diseño institucional de este tipo no hace sino aumentar el riesgo de anarquía, desorden y conflictos civiles y políticos, pues hace recaer todo el peso del andamiaje del poder político fiduciario en un principio de soberanía popular (Ashcraft, 1986; Gauthier, 1992; Tully 1993; Glanville, 2014). ${ }^{11}$

Locke recurre tácticamente a la teoría de un absolutista partidario de la libertad natural, William Barclay, y a través de ella refuta cabalmente los cargos de anarquía de la obra de Filmer (1991). ${ }^{12}$ Barclay (1600), en su defensa de la idea de que un inferior nunca podía castigar a un superior, sostenía que ni siquiera el pueblo en su conjunto podía sancionar, atacar o enjuiciar a su rey, con una excepción: si el rey deviene un tirano intolerable y ataca directamente a su pueblo, éste, individual o colectivamente, tiene derecho a defenderse por la fuerza. Esto se justifica porque la autopreservación constituye la razón original por la que el pueblo instituyó el gobierno (monárquico). Locke muestra así que incluso el morigerado Barclay está

11 William Atwood, un whig moderado coetáneo de Locke, en una objeción distintivamente anti-plebeya, sostiene que la tesis lockeana da un peso excesivo al elemento popular, lo cual conducirá a: "to be a mere Commonwealth, or absolute Anarchy, wherein every body has an equal share in the Government, not only Landed-men, and others with whom the ballance of power has rested by the Constitution, but Copy-holders, Servants, and the very Faeces Romuli, which not only make a quiet Election impracticable, but bring in a deplorable Confusion" (Goldie, 1999, 47). Esto ilustra bien a las claras que la teoría política revolucionaria de Locke no sólo tuvo que confrontar los argumentos de los absolutistas, sino muy particularmente una gran mayoría de los whigs, que veían a Locke como un radical (Jones, 1961; Goldie, 1980; Dickinson, 1978, 71; Aschcraft, 1986, 572-573).

12 Aún cuando fue escrita entre 1628 y 1652, Patriarcha fue reeditada en 1680 para auxilio de los absolutistas de la época, que la utilizaron como artillería pesada contra el autor de los Two Treatises. 
dispuesto a admitir que cuando el monarca abusa de su poder pierde su condición: "returns to the state of private man, and the people become free and superior" (II.237). ${ }^{13}$ Pues bien, esto le sirve a Locke para evidenciar que ni siquiera el monarca absoluto está a resguardo del control popular: si incluso un absolutista admite esto, en modo alguno puede suponerse que el pueblo es un sujeto pasivo, tout court (II.239). Pero este argumento tiene más miga, pues en realidad no hacía sino confirmar el temor expresado por Filmer de que la doctrina de la libertad natural -incluso en su versión alienista- llevaba en su seno la semilla de la legitimación de la resistencia al poder político constituido. Porque sólo puede estar legitimado a resistir y a rebelarse quien tiene poder político autónomo, por lo que el argumento constituye un alegato en favor de la soberanía popular, independientemente de que en el contexto de las instituciones y del lenguaje político de la época tomara explícitamente o no ese nombre (II.205-210).

A partir de esa posición de principio, para aquietar tácticamente la feroz oposición de los conservadores de la época, Locke desmiente el riesgo de anarquía con otros dos tipos de argumentos complementarios. En primer lugar, expone que las personas no tienden a rebelarse cuando la opresión es moderada o los asuntos a dirimir son menores (II.21, II.209, II.225, II.137, II.158, II.229, II.230), sino que la rebelión se produce cuando se percibe una injusticia generalizada o cuando la opresión afecta directamente a una minoría, pero tiene visos de poder extenderse a todos (II.209, II.230). ${ }^{14}$ En segundo lugar, afirma que la eventual existencia de instituciones fiduciarias estables que permitan canalizar las reclamaciones, como el parlamento o los tribunales de justicia, hace menos probable la revolución que un régimen de monarquía absoluta (II.224).

El argumento termina con un corolario: lo que promueve el desorden es la opresión, no el ejercicio de la soberanía popular (II.92, II.111, II.152, II.158, II.163, II.210, II.224-2.230). Ninguna forma de gobierno garantiza absolutamente la libertad y los derechos, que están siempre expuestos al abuso (II.209). ${ }^{15}$ Sólo mediante el derecho a una rebelión autogobernada puede sustentarse eficazmente la libertad (II.226-229). Lo que perturba la paz del mundo es el estado de opresión, violencia, ilegalidad y pillaje, no rebelarse contra tales arbitrariedades:

"But if they who say it lays a foundation for rebellion mean that it may occasion civil wars or intestine broils to tell the people they are absolved from obedience when illegal attempts are made upon their liberties or properties, and may oppose the unlawful violence of those who were their magistrates when they invade their properties, contrary to the trust put in them, and that, therefore, this doctrine is not to be allowed, being so destructive to the peace of the world; they may as well say, upon the same ground, that honest men may not oppose robbers or pirates, because this may occasion disorder or bloodshed" (II.228).

13 De hecho, el argumento de Barclay era una réplica al de George Buchanan (1766 [1579]), según el cual cuando un monarca deviene un tirano está disolviendo el pacto constitutivo con su pueblo, pierde sus derechos y, el pueblo o individuos particulares, pueden proceder en su contra (cf. II.19).

14 Locke sacó esta lección cuando los whigs se negaron a apoyar la revolución en favor de los derechos de la minoría de los dissenters en 1681-1683 (Ashcraft, 1986).

15 Esto es, para Locke los gobernantes a quienes se ha confiado el poder fiduciario no son inherentemente corruptos, sino corruptibles. De otro modo, la relación fiduciaria nacería muerta. 
Puesto que en el absolutismo el gobernante no rinde cuentas ante nadie, puede ser absolutamente parcial, avivando por tanto las revueltas (II.90-94). Locke tiene plena consciencia de que también puede haber parcialidad en los sistemas de gobierno fundados en el pueblo libre, pero considera que esa parcialidad será siempre en favor de la libertad:

"Whatsoever cannot but be acknowledged to be of advantage to the society, and people in general, upon just and lasting measures, will always, when done, justify itself" (II.158). ${ }^{16}$

\section{Conclusión}

La defensa de la soberanía popular de Locke constituye un desarrollo de un presupuesto ilustrado: cada persona es naturalmente libre, tiene capacidad y derecho para juzgar por sí misma, y, por eso mismo, tiene un derecho natural a resistir cualquier dominación. Locke no admite que el único sentido común válido sea el que subyace a -y se proyecta desde- las instituciones heredadas, a menos que cuenten con el consentimiento fiduciario del pueblo. El sentido común que debe regir la reflexión y la acción políticas es aquél que promueva la libertad política recíproca de todos los ciudadanos. Locke dedicó acrisolados argumentos a desmontar las falacias de quienes atacaban la legitimidad y la fiabilidad de las opiniones de los que no participaban del consenso político de la época, como hacían los realistas anglicanos con los dissenters (Ashcraft, 1986). ${ }^{17}$

Para Locke, la facultad de juzgar, aun cuando siempre se desarrolla en el contexto de una práctica o de una institución, incluye también la capacidad reflexiva de examinar, reevaluar, criticar y sopesar las propias tradiciones heredadas que otorgan significado a esas prácticas. Por eso, la relación fiduciaria entre gobernantes y gobernados pivota de un modo fundamental sobre la formación crítica del juicio político de los gobernados. ${ }^{18} \mathrm{Y}$,

16 En Locke no queda claramente explicitado qué grupos socioeconómicos componen el "pueblo", por lo que ésta sigue siendo una discusión abierta (Goldie, 1980; Wood, 1983, 194, nota 51). Sin embargo, Aschcraft (1986) considera que el lenguaje de los levellers -que, a su juicio, claramente incluía a las clases más bajas en la noción "pueblo", precisamente con el propósito de dotarlas de existencia política- razonablemente estaba presente en las formulaciones radicales que reaparecieron en la década de 1680: "The radicals in 1689, however, unlike the Whigs, did not dissociate themselves from the imputation attached to their language suggesting that 'the people' were 'copyholders' or artisans, that the franchise should be extended, or that the people at large were a corporative body" (Ashcraft, 1986, 564-565). Sostiene, además, que resulta por completo incongruo que el contenido de los Two Treatises pudiera ir destinado a convencer a la aristocracia terrateniente, "but rather to the urban merchants, tradesman, artisans, and independent small gentry who constituted the social foundations for any radical political theory -including Locke's- in seventeenth-century England" (Ashcraft, 1986, 578-579).

17 La mayor parte del libro I de An essay concerning human understanding (Locke, 1975 [1690]) está dedicado a exponer la circularidad tautológica de este tipo de razonamientos: "And then their argument stands thus: "the principles which all mankind allow for true, are innate; those that men of right reason admit, are the principles allowed by all mankind; we, and those of our mind, are men of reason; therefore we agreeing, our principles are innate;' which is a very pretty way of arguing, and a short cut to infallibility" (Locke, 1975, 1.3.20).

18 En contra de este presupuesto teórico de Locke, podría aducirse que los miembros de las sociedades modernas han sido modelados por las instituciones políticas en las que han crecido. De modo que su sentido común político estaría permeado y se fundaría en esas instituciones, y no al revés. Cuestión esta que nos conduciría a revisitar un dilema muy propio de la filosofía política contemporánea, al que podríamos llamar la "discusión entre 
por eso también, el reconocimiento del derecho y el deber naturales de rebelarse contra la opresión conlleva el reconocimiento de la soberanía popular, fundada en la libertad política inalienable de cada uno de los individuos.

Es en este sentido que la teoría republicana moderna de la concepción revolucionaria de la soberanía popular tuvo un eslabón fundamental en la obra John Locke. Para el absolutismo, el principal -el soberano- es el monarca (o, en otro sentido, dios; cf. Mundó 2017a), y soberanía y libertad política son términos en tensión permanente. En cambio, el grueso del republicanismo moderno triunfó iusfilosóficamente infundiendo en nuestro ordenamiento jurídico una idea-fuerza que reconcilia libertad política y soberanía: primero, haciendo la libertad política inalienable; segundo, concibiendo al pueblo libre como soberano; tercero, transformando a este soberano en principal; $y$, cuarto, convirtiendo al representante o a la autoridad política en un poder político fiduciario, en un agente, deponible por el principal, cuando quebranta la confianza otorgada.

Sin embargo, cabe señalar una cautela final acerca del mecanismo fiduciario de Locke, el cual parece estar muy bien fundamentado hacia atrás ( si los gobernantes violan la confianza otorgada, entonces el ejercicio del poder delegado regresa a las manos del pueblo libre), pero que resulta conceptualmente más problemático hacia delante (los humanos naturalmente libres "consienten" en formar una sociedad política e instituir un poder político fiduciario). La naturaleza y el grado de verosimilitud de ese consentimiento entraña problemas filosófico-políticos y prácticos de mucho calado, no sólo para el contexto histórico de Locke, sino, señaladamente, en punto a la articulación de cualquier propuesta política republicana democrática para el mundo contemporáneo (cf. Fox-Decent, 2011; Gold, 2018).

\section{Referencias}

Ashcraft, R. (1986), Revolutionary Politics and Locke's Two Treatises of Government, Princeton: Princeton University Press.

Bacon, N. (1647), An Historical Discourse of the Uniformity of the Government of England, London: Matthew Walbanke.

Barclay, W. (1600), De regno et regali potestate, París.

Barker, E. (1934), «Introduction», en: Gierke, O., Natural Law and the Theory of Society, 1500-1800, trad. E. Barker, Cambridge: Cambridge University Press.

Buchanan, G. (1766 [1579]), De jure regno apud Scotos, trad. Philatethes, Philadelphia: Andrew Steuart.

Cicero, M.T. (1928), De Officiis, trad. Walter Miller, London: William Heinemann.

Criddle, E.J., Miller, P.B. y Sitkoff, R.H. (2019), The Oxford Handbook of Fiduciary Law, Oxford: Oxford University Press.

Criddle, E.J. (2014), «A Sacred Trust of Civilization: Fiduciary Foundations of International Law», en: Gold, A.S. y Miller, P.B. (eds.), Philosophical Foundations of Fiduciary Law, Oxford: Oxford University Press, pp. 363-387.

los dos Rawls": si -como sostendría el primer Rawls (1971)- la tolerancia es un axioma, o si -como apuntaría el segundo (Rawls, 1999) - en realidad la tolerancia no es más que un teorema, cuyos axiomas de partida serían las instituciones políticas preexistentes. 
Dickinson, H.T. (1978), Liberty and Property: Political Ideology in Eighteenth-Century Britain, New York: Holmes and Meier.

Domènech, A., (2009), «Droit, droit naturel et tradition républicaine moderne», en: Gauthier, F., Belissa, M. y Bosc, Y. (dirs.), Républicanismes et droit naturel à l'époque moderne. Des humanistes aux révolutions des droits de l'homme et du citoyen, París: Kimé, pp. 17-30.

Ferguson, A. (1995 [1767]), An Essay on the History of Civil Society, Cambridge: Cambridge University Press.

Filmer, R. (1991 [1648]), Patriarcha and other political writings, ed. J.P. Sommerville, Cambridge: Cambridge University Press.

Fox-Decent, E. (2011), Sovereignty's Promise. The State as Fiduciary, Oxford: Oxford University Press.

Frankel, T. (2011) Fiduciary Law, Oxford: Oxford University Press.

Gauthier F. (1992), Triomphe et mort du droit naturel en Révolution. 1789-1795-1802, Paris: PUF (reedición Syllepses, 2014).

Glanville, L. (2012), Sovereignty and the Responsibility to Protect, Chicago/London: Chicago U.P.

Gold, A.S. (2018), «The State as a Wrongful Fiduciary», en: Criddle, E.J. et al. (eds.), Fiduciary Government, Cambridge: Cambridge University Press, pp. 183-202.

Goldie, M. (1980), «The roots of true whiggism, 1688-94», History of Political Thought, $1(2), 195-236$.

Gough, J.W. (1950), John Locke's Political Philosophy, Oxford: Oxford University Press.

Grocio, H.(1987 [1625]), Del derecho de presa; Del derecho de la guerra y de la paz: textos de las obras "De iure praedae" y "De iure belli ac pacis", edición bilingüe, traducción, introducción y notas de Primitivo Mariño Gómez, Madrid: Centro de Estudios Constitucionales.

Harrington, J. (1656), The Commonwealth of Oceana, London.

Hobbes, Th. (2012 [1651]), Leviathan, ed. Noel Malcolm, London: Clarendon Press.

Horne, M. (1646), Mirrour of Justices, London: Matthew Walbanke.

Johnston, D. (1998), «Trusts and Trustlike Devices in Roman Law», en: Helmholz, R. y Zimmermann, R. (eds.), Itinera Fiduciae; Trust and Truehand in Historical Perspective, Berlin: Duncker \& Humblot.

Jones, J.R. (1961), The first Whigs: the politics of the exclusion crisis, 1678-83, Oxford: Oxford University Press.

Kuttner, S. (1982), «The revival of jurisprudence», en: Studies in the History of Medieval Canon Law, Aldershot: Routledge, pp. 299-323.

Locke, J. (1988 [1681-1689]), Two Treatises of Government, ed. Peter Laslett, 2nd. ed., reprinted, Cambridge: Cambridge University Press.

Locke, J. (1963 [1689]), A Letter Concerning Toleration, The Hague: Martinus Nijhoff.

Locke (2006 [1667]), An Essay Concerning Toleration. And Other Writings on Law and Politics, 1667-1683, edited with and introduction and notes by J.R. Milton and P. Milton, Oxford: Oxford University Press.

Locke, J. (1967 [1660]), Two Tracts on Government, edited with and introduction, notes and translation by Philip Abrams, Cambridge: Cambridge University Press.

Maine, H. (1963 [1861]), Ancient law: its connection with the early history of society and its relation to modern ideas, Boston: Beacon Press. 
Maitland, F.W. (1913 [1900]), «Introduction», en: Gierke, O., Political Theories of the Middle Age, Cambridge: Cambridge University Press, pp. 1-48.

Milton, J. (1991 [1649]), «The Tenure of Kings and Magistrates», in Political Writings, Martin Dzelzainis ed., Claire Gruzelier trad., Cambridge: Cambridge University Press.

Mundó, J. (2018), «De la retórica absolutista de la propiedad al sentido común de la propiedad limitada», Sin Permiso, 16, pp. 35-63.

Mundó, J. (2017b), «Locke〉s property in historical perspective: natural law and the shaping of modern political common sense», Analele Universitatii din Craiova-Seria Filosofie. 40(2), pp. 19-40.

Mundó, J. (2017a), «La constitución fiduciaria de la libertad política. (Por qué son importantes las coyunturas interpretativas en filosofía política)», Isegoría. Revista de Filosofía Moral y Política, 57 (Julio-Diciembre), pp. 433-454.

Mundó, J. (2015), «Political freedom in Locke's republicanism», en: Bosc, Y. et al. (dirs.), Cultures des republicanismes. Pratiques-Représentations-Concepts de la Révolution à aujourd'hui, París: Édicions Kimé, pp. 103-117.

Mundó, J. (2005), «Autopropiedad, derechos y libertad (¿debería estar permitido que uno pudiera tratarse a sí mismo como a un esclavo?)», en: Bertomeu, M.J. et al. (eds.), Republicanismo y democracia, Buenos Aires, Miño y Dávila editores, pp. 187-208.

Phillipson, N.; Skinner, Q. (1993), Political Discourse in Early Modern Britain, Cambridge: Cambridge University Press.

Pocock, J.G.A. (1987), The Ancient Constitution and the Feudal Law, Cambridge: Cambridge University Press.

Pufendorf, S. (1729 [1672]), On the law of nature and nations, ed. Jean Barbeyrac, trad. Basil Kennett, London.

Purdy, J. y Fielding, K. (2007), «Trustees, Guardians: Private-Law Concepts and the Limits of Legitimate State Power», Law and Contemporary Problems, 70(3), pp. 165-211.

Rawls, J. (1999), The Law of Peoples, Cambridge, MA: Harvard University Press.

Rawls, J. (1971), A Theory of Justice, Cambridge, MA: Harvard University Press.

Rousseau, J.J. (1762), Du contrat social, édité par la bibliothèque numérique romande, www.ebooks-bnr.com

Sydney, A. (1698), Discourses concerning Government, London.

Tierney, B. (2014), Liberty \& Law. The Idea of Permissive Natural Law, 1100-1800, Washington, D.C.: The Catholic University of America Press.

Tierney, B. (1997), The idea of natural rights: Studies on natural rights, natural law, and church law, Grand Rapids: Eerdmans Publishing Company.

Tönnies, F. (1972 [1880]), Gemeinschaft und Gesellschaft: Grundbegriffe der Reinen Soziologie, Darmstadt: Wissenschaftliche Buchgesellschaft.

Tuck R. (1979), Natural rights theories: Their origin and development, Cambridge: Cambridge University Press.

Wood, N. (1983), The Politics of Locke's Philosophy, Berkeley/Los Angeles: University of California Press. 